\title{
Blockade of D1 Dopamine Receptors in the Ventral Tegmental Area Decreases Cocaine Reward: Possible Role for Dendritically Released Dopamine
}

\author{
Robert Ranaldi ${ }^{1}$ and Roy A. Wise ${ }^{2}$ \\ ${ }^{1}$ Department of Psychology, Queens College, City University of New York, Flushing, New York 11367, and ${ }^{2}$ Behavioral \\ Neuroscience Branch, Intramural Research Program, National Institute on Drug Abuse, National Institutes of Health, \\ Baltimore, Maryland 21224
}

\begin{abstract}
This study was designed to assess the involvement of D1 dopamine actions in the ventral tegmental area (VTA) on intravenous cocaine self-administration. Rats were trained to selfadminister intravenous injections of cocaine $(1.0 \mathrm{mg} / \mathrm{kg}$ per injection) on a fixed-ratio 1 (FR-1) schedule or a progressive ratio (PR) schedule of reinforcement and then were tested under the influence of bilateral VTA injections of the D1 dopamine receptor antagonist $\mathrm{SCH} 23390$ or the 5-HT2 receptor antagonist ketanserin. SCH 23390 increased cocaine self-
\end{abstract}

administration on the FR-1 schedule but decreased it on the PR schedule. Injections of ketanserin were ineffective, as were injections of SCH 23390 in a site $1 \mathrm{~mm}$ dorsal or $1 \mathrm{~mm}$ rostral to the effective VTA site. These data suggest a role for dendritically released dopamine, presumably acting through $\mathrm{D} 1$ receptors located on the axons of GABAergic or glutamatergic inputs to the VTA, in the effectiveness of cocaine reward.

Key words: drug abuse; reinforcement; dendritic release; motivation; operant learning; progressive ratio schedule
Brain dopamine (DA) plays important roles in the rewarding effects of natural rewards such as food (Wise et al., 1978; Ettenberg and Camp, 1986a), water (Gerber et al., 1981; Ettenberg and Camp, 1986b), and sexual contact (Pfaus and Phillips, 1989) and in the laboratory reward of lateral hypothalamic electrical stimulation (Fouriezos and Wise, 1976; Franklin, 1978; Wise and Rompré, 1989). The mesocorticolimbic DA system, which originates in the ventral tegmental area (VTA) and terminates in various forebrain structures (Bjorklund and Lindvall, 1986), is also implicated in the rewarding effects of several drugs of abuse, including cocaine, amphetamine, heroin, and nicotine (Wise, 1996; Bardo, 1998). Each of these drug reinforcers causes elevations in extracellular dopamine levels at the axon terminals of the mesocorticolimbic DA system (Zetterström et al., 1983; Di Chiara and Imperato, 1988; Moghaddam and Bunney, 1989). In the case of cocaine, the enhanced extracellular DA concentrations are caused by a blockade of the reuptake of DA back into presynaptic terminals. Destruction of dopaminergic terminals (Roberts et al., 1977) or dopaminergic synaptic targets (Zito et al., 1985) in the nucleus accumbens (NAcc), a mesolimbic terminal region, disrupts responding maintained by cocaine. Injection of D1 dopamine receptor antagonists into the NAcc (Maldonado et al., 1993; McGregor and Roberts, 1993), the medial prefrontal cortex (McGregor and Roberts, 1995), or, to a lesser extent, the amygdala (McGregor and Roberts, 1993), reduces cocaine re-

\footnotetext{
Received Jan. 16, 2001; revised April 18, 2001; accepted May 21, 2001.
}

This research was initiated at Concordia University (Montréal, Québec, Canada), where it was supported by grants from the Medical Research Council of Canada, the National Institute on Drug Abuse of the United States (Grant DA1720), and Fonds pour la Formation de Chercheurs et l'Aide à la Recherche (Québec), and completed at the University of Mississippi Medical Center under a National Institute on Drug Abuse contract. We thank Zafiro Koty for excellent technical assistance.

Correspondence should be addressed to Dr. Robert Ranaldi, Department of Psychology, Queens College, City University of New York, 65-30 Kissena Boulevard, Flushing, NY 11367. E-mail: Robert_Ranaldi@qc.edu.

Copyright (C) 2001 Society for Neuroscience $0270-6474 / 01 / 215841-06 \$ 15.00 / 0$ ward. Thus it is widely assumed that it is dopamine released at the terminals of the mesocorticolimbic system that is important for reward function (Fibiger, 1978; Wise, 1978; Koob and Bloom, 1988; Wise, 1996; Berridge and Robinson, 1998).

In addition to increasing extracellular levels of DA at the level of the axon terminals of the mesocorticolimbic system, cocaine also increases extracellular DA at the level of the dendrites in the VTA (Bradberry and Roth, 1989; Chen and Reith, 1994). Although dendritically released DA has been shown to be involved in the acute locomotor effects of psychostimulants (Jackson and Kelly, 1983; Stewart and Vezina, 1989; LaHoste and Marshall, 1990), a role for dendritically released dopamine in reward function has not been reported. The neurochemical and neuroanatomical arrangements of the VTA, however, suggest that dendritically released DA may indeed be involved in cocaine reward. Dendritically released DA in the VTA acts on D1 receptors located on the terminals of GABAergic and glutamatergic inputs originating in forebrain regions (Sesack and Pickel, 1992; Smith et al., 1996; Steffensen et al., 1998). GABA and glutamate in the VTA modulate the activity of dopaminergic and GABAergic output cells (Albin et al., 1992; Nakanishi, 1992; Overton and Clark, 1992; Kalivas, 1993; Zhang et al., 1994; Christoffersen and Meltzer, 1995). Thus, by modulating the release of GABA and glutamate, which in turn modulate DA cell activity and output, dendritically released DA could play a significant role in cocaine reward. We tested this hypothesis by investigating the effects of intra- and peri-VTA injections of the D1 DA receptor antagonist SCH 23390 or the 5-HT2 receptor antagonist ketanserin on cocaine selfadministration in rats. Ketanserin was tested as a control because, in addition to being a potent antagonist at the D1 DA receptor, SCH 23390 is a weak antagonist at the 5-HT2 receptor, which is also found in the VTA. Our results support the hypothesis that dendritically released DA in the VTA affects the rewarding effectiveness of cocaine. 


\section{MATERIALS AND METHODS}

Subjects and surgery. Subjects were male Long-Evans rats (Charles River Canada, Saint Constant, Québec, Canada; and Harlan, Indianapolis, IN) weighing between 350 and $400 \mathrm{gm}$ at the time of surgery. Each was kept on a $12 \mathrm{hr}$ light/dark cycle with the dark phase starting at 7 A.M. and had free access to food (Purina rat chow) and water except during selfadministration sessions. Each rat was implanted, under sodium pentobarbital anesthesia $(65 \mathrm{mg} / \mathrm{kg}$, i.p.), with bilateral guide cannulas $(20$ gauge) aimed at the VTA or at control sites either $1 \mathrm{~mm}$ rostral or $1 \mathrm{~mm}$ dorsal to the VTA. For guide cannula implantations into the VTA, the flat-skull (Paxinos and Watson, 1986) coordinates were $5.6 \mathrm{~mm}$ caudal to bregma, $\pm 2.2 \mathrm{~mm}$ lateral to the midline (angled at $10^{\circ}$ toward the midline to bypass the sagittal sinus), and $7.3 \mathrm{~mm}$ below the surface of the skull. For the rostral control site, the coordinates were $4.6 \mathrm{~mm}$ caudal to bregma, $\pm 2.2 \mathrm{~mm}$ from the midline, and $7.3 \mathrm{~mm}$ below the surface of the skull. For the dorsal control site, the coordinates were $5.6 \mathrm{~mm}$ caudal to bregma, $\pm 2.2 \mathrm{~mm}$ from the midline, and $6.3 \mathrm{~mm}$ below the surface of the skull. Obturators extended $1 \mathrm{~mm}$ beyond the guide cannulas and were kept there until the time of testing.

While under anesthesia, each rat was fitted with a permanently indwelling jugular catheter. An incision was made in the neck and the jugular vein was isolated and opened. A Silastic intravenous catheter (Dow Corning, Midland, MI) was inserted into the vein so that the tip penetrated to a position just short of the right atrium. The other end of the catheter was fed subcutaneously to the back of the neck and exited through an opening at the back of the skull. A bent 22 gauge stainless steel tube was inserted into the catheter and secured to the rat's skull with dental cement anchored by stainless steel screws. This tube served as a connector between the intravenous catheter and the drug infusion line. The catheter was flushed with a heparin-saline solution $(200 \mathrm{U} / \mathrm{ml})$ immediately after surgery and daily thereafter.

Cocaine self-administration training. One day after surgery, the animals began cocaine self-administration training. All self-administration sessions (training and test) were conducted during the dark phase. Each animal was placed daily in a $26 \times 26 \times 30 \mathrm{~cm}$ operant chamber equipped with an operant lever mounted $10 \mathrm{~cm}$ from the floor. A white cue light was mounted $3 \mathrm{~cm}$ above the lever, and each cage had a hanging water bottle. The rat was connected by polyethylene tubing, through a fluid swivel, to a syringe in a syringe pump (Razel; $1 \mathrm{rpm}$ ). Each lever press activated the syringe pump and cue light for $14 \mathrm{sec}$, causing the intravenous delivery of $1.0 \mathrm{mg} / \mathrm{kg}$ cocaine in a $0.125 \mathrm{ml}$ volume of saline. During drug delivery, lever presses were counted but had no other consequence. Thus, the rats learned to lever press under a fixed ratio 1 (FR-1) schedule of reinforcement. Some rats were tested on this schedule of reinforcement, whereas others were switched, after responding stabilized, to a progressive ratio (PR) schedule. Stable responding on the FR-1 schedule was defined as three consecutive sessions during which the total number of responses did not vary by $>10 \%$ from the mean of the three sessions; rats met this criterion between 11 and 20 training sessions.

On a PR schedule of reinforcement, the ratio of responses per inf usion was increased after each infusion according to an exponential function. In the present study, the response requirements in the progression were calculated by the formula, responses $=5 \times e^{(\mathrm{inj} \# \times 0.2)}-5$. The ratios in the progression were $1,2,4,6,9,12,15,20,25,32,40,50,62,77,95$, and so on. Eventually, as the ratio requirement increased, the rats ceased to respond. The step at which rats stopped responding was referred to as the break point (BP). For the present experiments, the BP was operationally defined as the final ratio completed within $1 \mathrm{hr}$ of the previously earned injection. A stable BP was operationally defined as three consecutive BPs that did not differ by $>10 \%$ from their mean; rats met this criterion between 15 and 20 training sessions.

Microinjections of SCH 23390 or ketanserin. On test days, the animals were pretreated with VTA microinjections of SCH 23390 or ketanserin. Fifteen rats were tested under the influence of intra-VTA injections of SCH 23390, and 10 were tested under intra-VTA ketanserin under the FR-1 schedule of reinforcement. Ten rats were tested with intra-VTA injections of SCH 23390 under a PR schedule of reinforcement. Four rats were tested under a PR schedule with microinjections of SCH 23390 in sites just rostral to the VTA, and five were tested with SCH 23390 in sites just dorsal to the VTA site.

Just before these test sessions, the obturator was removed from one of the guide cannulas, and a stainless steel injector cannula was inserted into that guide cannula for each animal. The injector extended beyond the guide cannula by $1 \mathrm{~mm}$. The injector was connected through polyethylene tubing to a $10 \mu$ l Hamilton (Reno, NV) syringe that was preloaded with
$\mathrm{SCH} 23390(1,2$, or $4 \mu \mathrm{g} / 0.5 \mu \mathrm{l})$, ketanserin $(2,4$, or $8 \mu \mathrm{g} / 0.5 \mu \mathrm{l})$ or vehicle (of which $96 \%$ of the volume consisted of artificial CSF and the rest of methanol). The test compound was delivered by motorized syringe pump in a volume of $0.5 \mu \mathrm{l}$ over $30 \mathrm{sec}$. The injector was kept in place for an additional $60 \mathrm{sec}$. The injector was then removed, and the obturator was replaced into the guide cannula. This procedure was repeated for the contralateral side. At the end of the second microinjection, the rat was placed in the operant chamber, and the test session (either FR-1 or PR) was started.

The animals were tested at $4 \mathrm{~d}$ intervals with as many of the doses or vehicle as possible; $3 \mathrm{~d}$ of treatment-free testing intervened between microinjection treatments. If the total number of injections on the session after the test session did not fall within $10 \%$ of the mean of the three sessions preceding the test session, then the data from that test session were not used. If after a test session, baseline response rates did not meet the stability criterion (three consecutive sessions in which the total number of injections per session was within $10 \%$ of the mean for the three sessions), treatment-free testing continued. If more than seven sessions passed in which the stability criterion was not met, the rat was removed from the experiment; two animals were removed for this reason. Animals were also removed from the experiment when catheters were blocked or began to leak or when head assemblies became dislodged. Sixteen of the FR-1 animals and seven of the PR animals failed to complete testing at one or more dose levels.

Histology. After its last test session, each rat was anesthetized with sodium pentobarbital, perfused with saline followed by $10 \%$ formalin, and decapitated. The brains were removed and stored in $10 \%$ formalin for at least $7 \mathrm{~d}$ before being cut in $40 \mu \mathrm{m}$ serial sections, stained with thionin, and inspected for cannula implantation and injection sites.

Data analysis. The total number of inf usions per session for the FR-1 or PR schedule was analyzed. Separate one-way ANOVAs were conducted on the data from the groups receiving intra-VTA doses of SCH 23390 or ketanserin under the FR-1 schedule of reinforcement. A separate one-way ANOVA was conducted on the data from the group receiving intra-VTA doses of SCH 23390 under the PR schedule. A final one-way ANOVA was conducted on the data from the groups receiving the $4.0 \mu \mathrm{g} / 0.5 \mu \mathrm{l}$ dose of SCH 23390 in the VTA, the site just dorsal to the VTA, and the site just rostral to the VTA. Site comparisons were made using Scheffé tests. Because not all animals completed every treatment condition in either experiment, we used a between-subjects ANOVA model. A within-subjects model would have overestimated statistical significance; the between-subjects model is more conservative.

Drugs. Cocaine hydrochloride (National Institute on Drug Abuse, Rockville, MD) was dissolved in saline. SCH 23390 and ketanserin (Research Biochemical Inc., Natick, MA) were dissolved in $4 \%$ methanol and $96 \%$ artificial CSF.

\section{RESULTS}

Microinjections of SCH 23390 into the VTA produced a doseorderly increase in the number of cocaine infusions selfadministered on an FR-1 schedule of reinforcement (Fig. 1a) $\left(F_{(3,17)}=13.86 ; p<0.001\right)$. At the highest dose, SCH 23390 increased cocaine intake to values twice as high as were observed after control vehicle injections. Response records taken in the baseline (no injection) and SCH 23390 conditions both showed well spaced cocaine intake that continued to be regular throughout the period of cocaine availability (Fig. 1b). However, the rate of cocaine intake was higher in the SCH 23390 condition than in the baseline or vehicle condition, especially during the first half of the test sessions. On average, the animals responded approximately once every 4 min under the high-dose SCH 23390 condition and once every $7 \mathrm{~min}$ under the baseline or vehicle condition. Microinjections of ketanserin into the VTA did not affect rate of cocaine self-administration (Fig. $1 a)\left(F_{(3,18)}=0.23 ; p>0.9\right)$.

In the case of the PR schedule, microinjections of SCH 23390 decreased responding (Fig. $2 a)\left(F_{(3,30)}=12.38 ; p<0.001\right)$. At the highest dose, $\mathrm{SCH} 23390$ reduced the mean number of cocaine infusions to $27 \%$ of the mean observed under vehicle control conditions. Cumulative response records taken in the vehicle condition showed alternations between periods of high response 
Fixed-ratio schedule of reinforcement

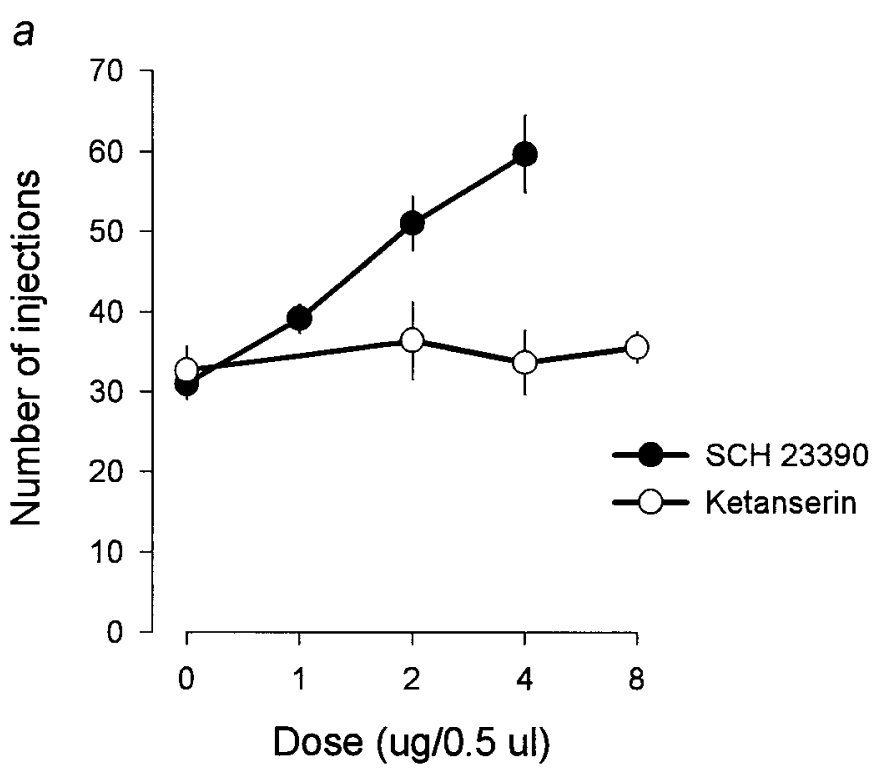

$b$
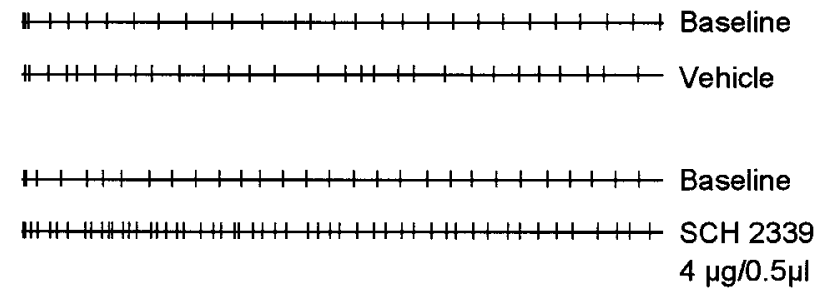

1 hour

Figure 1. a, Mean \pm SEM effects of SCH 23390 (and ketanserin) on cocaine self-administration under an FR-1 schedule of reinforcement. $b$, Event records reflecting the response rate and pattern of responding for a subject under baseline conditions and after vehicle or SCH 23390 treatment. Note the immediate acceleration and subsequent return toward a normal response rate after SCH 23390 treatment.

rates followed by postreinforcement pauses (no responding) that are typically seen during cocaine self-administration on PR schedules of reinforcement. Cumulative response records taken in the SCH 23390 condition also showed this typical PR pattern of responding, except that responding ended earlier in the session at lower final response ratios (Fig. $2 b$ ). Whereas the animals made a mean of 57 lever presses for the final earned injection under the vehicle condition, they made means of only 33, 14, and 4 responses for the final earned injections under the 1,2 , and $4 \mu \mathrm{g} / 0.5$ $\mu \mathrm{l} \mathrm{SCH} 23390$ conditions, respectively (Table 1).

Microinjections of the $4 \mu \mathrm{g} / 0.5 \mu \mathrm{l}$ dose of SCH 23390 into a site $1 \mathrm{~mm}$ dorsal or into a site $1 \mathrm{~mm}$ rostral to the VTA injection site also produced decreases in PR responding, but these reductions were significantly smaller than those observed after microinjection of this dose of SCH 23390 into the VTA (Fig. 3) $\left(F_{(2,15)}=\right.$ $13.62 ; p<0.001)$. Scheffé comparisons between the VTA and the dorsal site and between the VTA and the rostral site confirmed that responding was significantly less depressed when SCH 23390 was injected dorsal or rostral to the VTA site $\left(F_{(1,15)}=21.07 ; p<\right.$ 0.001 ; and $F_{(1,15)}=14.94 ; p<0.01$, respectively).
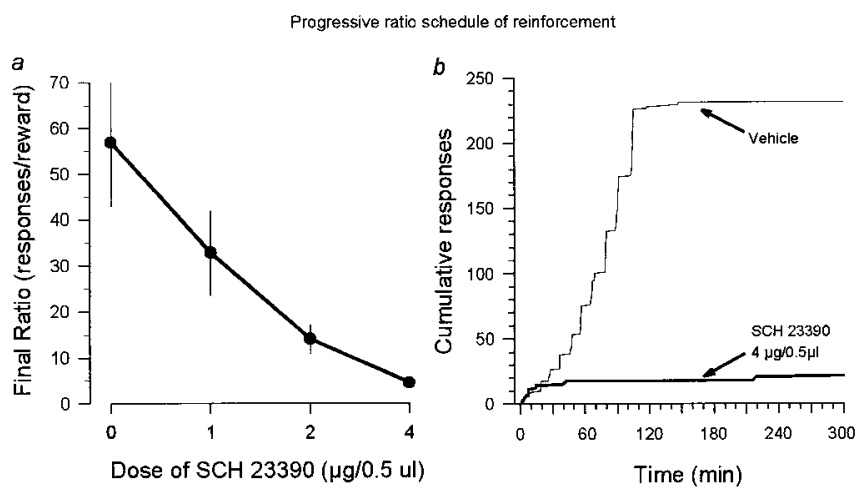

Figure 2. $a$, Mean \pm SEM effects of SCH 23390 on BP for cocaine self-administration under a PR schedule of reinforcement. $b$, Cumulative response records reflecting the total number of responses and the pattern of responding for a subject after vehicle or SCH $23390(4 \mu \mathrm{g} / 0.5 \mu \mathrm{l})$ treatment.

Figure 4 shows the locations of the cannula tips. Microinjections aimed at the anatomical control sites were $\sim 1 \mathrm{~mm}$ rostral and $1 \mathrm{~mm}$ dorsal to the VTA region (Fig. 4).

\section{DISCUSSION}

Microinjections of SCH 23390 into the VTA increased rates of cocaine self-administration on an FR-1 schedule of reinforcement and, at the same doses, decreased BPs on a PR schedule of reinforcement. Together these data suggest that blockade of D1 DA receptors in the VTA reduces the rewarding effectiveness of self-administered cocaine. The fact that intra-VTA injections of SCH 23390 affected response rates in opposite directions depending on the schedule of reinforcement under which the rats were responding argues against the possibility that VTA SCH 23390 had a simple, nonspecific effect on motoric output. Had $\mathrm{SCH}$ 23390 enhanced or impaired the ability of animals to perform the lever press response, then it would have produced changes in the same direction under the two schedules of reinforcement. Rather, the data suggest a motivational interpretation.

In the present study, animals responding under the FR-1 schedule and pretreated with intra-VTA SCH 23390 continued to display the pattern of regularly spaced infusions that was seen after no or vehicle pretreatment. Thus cocaine was still sufficiently rewarding to maintain stable responding under the $\mathrm{SCH}$ 23390 conditions. However, each earned injection satisfied (satiated) the animal for a shorter duration under SCH 23390 conditions than under normal conditions. Cocaine is thought to be effective because it elevates extracellular dopamine levels, and the generally accepted interpretation of neuroleptic-induced increases in stimulant self-administration is that increased dopamine concentrations are needed to overcome the competitive

Table 1. Effects of intra-VTA SCH 23390 on mean final ratios completed in the progressive ratio series and on mean cumulative responses

\begin{tabular}{llc}
$\begin{array}{l}\text { Dose of SCH } 23390 \\
(\mu \mathrm{g} / 0.5 \mu \mathrm{l})\end{array}$ & $\begin{array}{l}\text { Final ratio } \\
\text { completed }\end{array}$ & $\begin{array}{l}\text { Cumulative } \\
\text { responses }\end{array}$ \\
\hline Vehicle & $56.86 \pm 14.04$ & $255.25 \pm 71.63$ \\
1 & $32.78 \pm 9.10$ & $136.56 \pm 44.02$ \\
2 & $14.13 \pm 3.11$ & $47.00 \pm 12.66$ \\
4 & $4.44 \pm 0.85$ & $9.11 \pm 2.24$
\end{tabular}

Values are mean \pm SEM. 


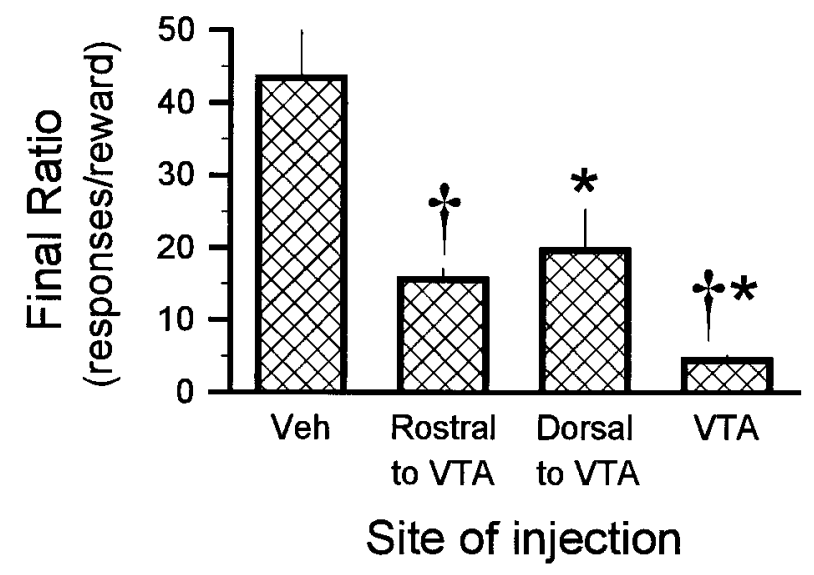

Figure 3. Depression of progressive ratio BP as a function of site of microinjection. The dorsal and rostral control sites were each $1 \mathrm{~mm}$ from the VTA site where the drug was most effective. The vehicle value represents the average of the vehicle data taken from the VTA and the dorsal and rostral sites. ${ }^{*}$ or $\dagger$ indicate paired comparisons that showed significant differences.

antagonism of dopamine receptors (Yokel and Wise, 1975, 1976; de Wit and Wise, 1977; Ettenberg et al., 1982).

The interpretation that blockade of VTA D1 receptors reduced the rewarding effectiveness of cocaine fits well with the decrease in BPs observed in rats responding under the PR schedule of reinforcement. In this paradigm, the number of lever presses required for successive injections was increased exponentially until the animal ceased continuing to respond. The BP, the response requirement at which the animal stops lever pressing, is taken as an index of the animal's motivation under a given reward condition (Richardson and Roberts, 1996). When a treatment reduces the BP for a given reward, it is thought to have done so by reducing the effectiveness of the rewarding event. By this test, again, intra-VTA SCH 23390 appears to reduce the rewarding effectiveness of self-administered cocaine. These findings are the first to suggest a functional role for dendritically released dopamine in reward function.

The present experiments with intra-VTA injections of ketanserin and peri-VTA injections of SCH 23390 were conducted to rule out the possibilities that the effects of intra-VTA injections of SCH 23390 were attributable to blockade of 5-HT2 receptors or to actions in distal sites. Although SCH 23390 is the classic antagonist of D1 DA receptors (Hyttel, 1983; Iorio et al., 1983) it also has high affinity for and antagonist actions at 5-HT2 receptors (Hicks et al., 1984; Bischoff et al., 1986; Hoyer et al., 1989; Briggs et al., 1991; Woodward et al., 1992; Ciccocioppo et al., 1997; Eberle-Wang et al., 1997). Ketanserin shares the ability to block 5-HT2 receptors (Leysen et al., 1981) but does not block D1 DA receptors. It is known that systemic injections of 5-HT2 antagonists fail to affect rate or BP in rats self-administering cocaine (Porrino et al., 1989; Lacosta and Roberts, 1993), suggesting that 5-HT2 receptors, in the VTA or elsewhere, are likely not involved in cocaine reward. However, there are 5-HT2 receptors in the VTA (Kalivas, 1993), and thus we used ketanserin to rule out the possibility that blockade of these receptors was significant in the effects of SCH 23390. The present data argue against this possibility. Ketanserin failed to affect cocaine self-administration, ruling out the possibility that 5-HT2 actions of SCH 23390 played a role in the SCH 23390 effects.

To address the possibility that intra-VTA injections of $\mathrm{SCH}$

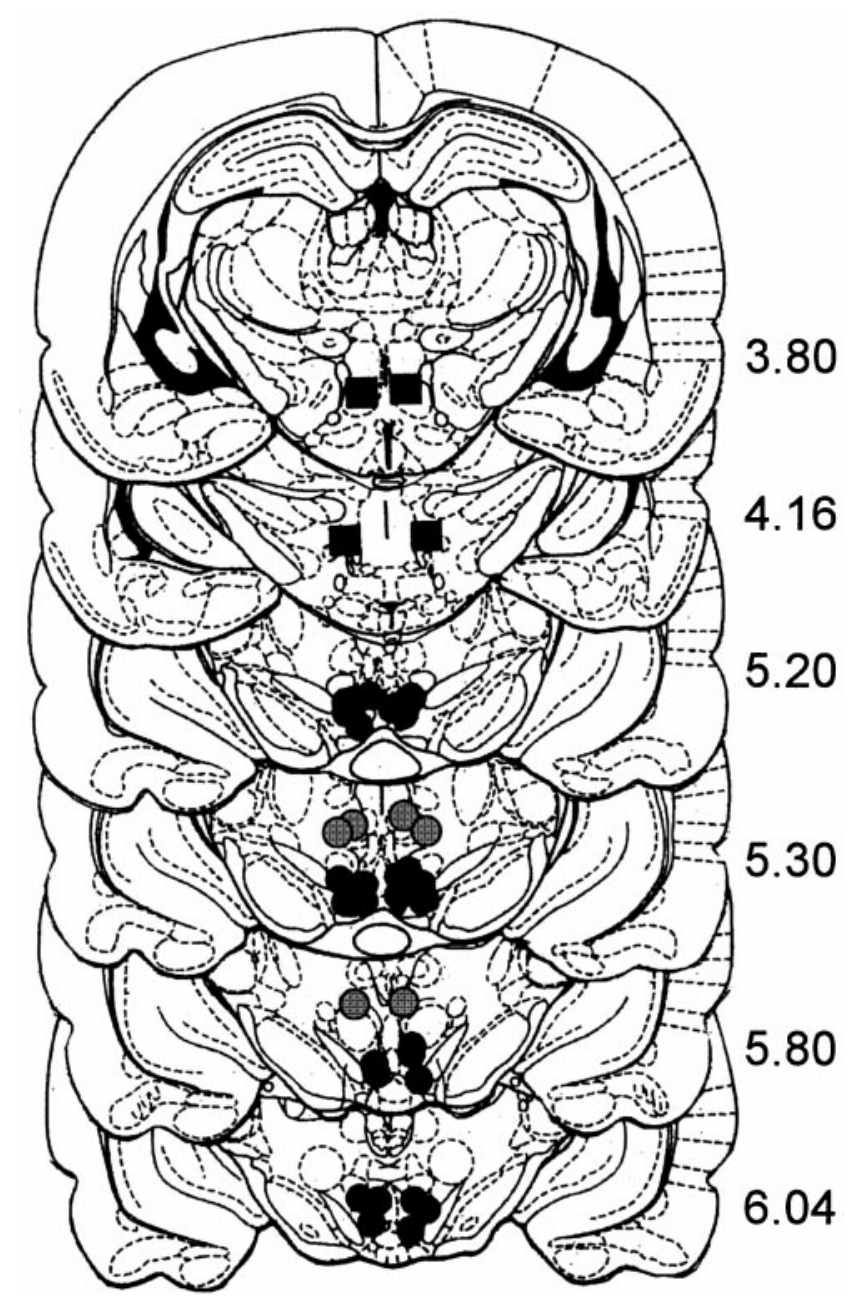

Figure 4. Histological reconstruction of injection sites adapted from Paxinos and Watson (1986). Black circles, SCH 23390 or ketanserin; gray circles, dorsal controls; black squares, rostral controls.

23390 diffuse to and act at distal sites, we investigated the effects of two peri-VTA injections of this compound on cocaine selfadministration. Injection of substances directly into the brain is associated with a hydraulic pressure that can drive the substance toward the pressure sinks of ventricles and extrapial spaces. The most prominent diffusion is up the cannula shaft, particularly if the cannula penetrates a ventricle (Johnson and Epstein, 1975; Wise and Hoffman, 1992). To assess this possibility, we tested injections just dorsal and just rostral to our VTA site. Although microinjections of SCH 23390 into each of these sites decreased responding on the progressive ratio schedule, in each case the effect was less than was seen with the primary VTA injections. This rules out the possibility of dorsal or rostral diffusion to a distal site of action; rather, it seems likely that diffusion to the VTA accounts for the weaker effects of injections into each of these control sites.

The mechanism of the reward-depressing effects of SCH 23390 in the VTA remains to be determined. The VTA is the site of origin of DA cells projecting to various forebrain structures (Bjorklund and Lindvall, 1986). There are no DA afferents to the VTA; thus the only source of DA here is dendritic release. Cocaine binds to DA transporters on the dendrites and dendritic spines of DA cells in the VTA (Ma et al., 1999). By blocking 
dendritic DA uptake, cocaine increases local DA concentrations (Kalivas and Duffy, 1993). There are no D1 DA receptors on dopaminergic (DAergic) neurons, however; D1 DA receptors in the VTA are localized on glutamate and GABA afferents to the VTA (Harrison et al., 1990; Herkenham et al., 1991; Yung et al., 1995; Lu et al., 1997), and the effect of DA at these receptors is to facilitate the release of these neurotransmitters (Starr, 1987; Cameron and Williams, 1993; Kalivas and Duffy, 1995). Glutamate excites VTA DAergic and non-DAergic neurons (Albin et al., 1992; Nakanishi, 1992; Carr and Sesack, 2000) and GABAergic neurons (Overton and Clark, 1992; Zhang et al., 1994; Christoffersen and Meltzer, 1995). GABA inhibits both DAergic neurons (Kalivas, 1993) and nearby GABAergic projection neurons, some of which, in turn, inhibit their dopaminergic neighbors, probably via local collaterals (Tepper et al., 1995). Thus dendritic DA, through D1 receptor activation, can affect local glutamate and GABA concentrations, which can, in turn, control DAergic neurons directly and, through GABA collaterals, indirectly. Given the known role of these DA cells in cocaine reward, any effect on their activity can be predicted to affect cocaine reward one way or the other. The role of GABAergic output cells in cocaine reward is not known, but some of them project to the NAcc, where they, too, might play a role in reward function.

The present finding that dendritically released DA in the VTA can play a significant role in cocaine reward adds a new level of complexity to our understanding of reward circuitry in particular and DAergic circuitry in general. DA transmission in the terminal regions of the mesocorticolimbic system has long been implicated in cocaine reward. The output neurons of NAcc project, through a complex anatomical cascade of GABAergic feedback, back to the VTA. Thus the VTA DAergic somata are positioned to release DA at both the cell bodies and the terminals of descending GABAergic pathways. Similarly, the mesocortical DA system releases DA at both the cell bodies and the descending terminals of the corticotegmental glutamate pathway. The present data support the hypothesis that feedback signals to the VTA contribute to reward function and to other functions of tegmental (both VTA and perhaps similarly substantia nigra) DAergic neurons. The mesocorticolimbic DA system is an important component of a general arousal system that plays significant roles in both the anticipation (Apicella et al., 1992; Schultz, 1997) and the reception (Wise and Rompré, 1989; Berridge and Robinson, 1998) of reward signals. It is not surprising that dysfunction of such a broadly projecting and servoregulated system plays a critical role in motivation and addiction (Fibiger, 1978; Wise, 1978; Koob and Bloom, 1988). Similarly, dysfunction of the nigrostriatal DA system contributes importantly to such divergent phenomena as the motor symptoms of Parkinson's disease and the cognitive and emotional symptoms of schizophrenia. The present findings suggest the possibility that dendritic release of DA in the substantia nigra plays roles in these syndromes as well.

\section{REFERENCES}

Albin RL, Makowiec RL, Hollingsworth ZR, Dure IV LS, Penney JB, Young AB (1992) Excitatory amino acid binding sites in the basal ganglia of the rat: a quantitative autoradiographic study. Neuroscience $46: 35-48$.

Apicella P, Scarnati E, Ljungberg T, Schultz W (1992) Neuronal activity in monkey striatum related to the expectation of predictable environmental events. J Neurophysiol 68:945-960.

Bardo MT (1998) Neuropharmacological mechanisms of drug reward: beyond dopamine in the nucleus accumbens. Crit Rev Neurobiol 12:37-67.

Berridge KC, Robinson TE (1998) What is the role of dopamine in reward: hedonic impact, reward learning, or incentive salience? Brain Res Rev 28:309-369.

Bischoff S, Heinrich M, Sonntag JM, Krauss J (1986) The D-1 dopamine receptor antagonist SCH 23390 also interacts potently with brain serotonin $\left(5-\mathrm{HT}_{2}\right)$ receptors. Eur J Pharmacol 129:367-370.

Bjorklund A, Lindvall O (1986) Catecholaminergic brainstem regulatory systems. In: Handbook of physiology: the nervous system, Vol IV, Intrinsic regulatory systems of the brain (Mountcastle VB, Bloom FE, Geiger SR, eds), pp 155-235. Bethesda, MD: American Physiological Society.

Bradberry CW, Roth RH (1989) Cocaine increases extracellular dopamine in rat nucleus accumbens and ventral tegmental area as shown by in vivo microdialysis. Neurosci Lett 103:97-102.

Briggs CA, Pollock NJ, Frail DE, Paxson DL, Rakowski RF, Kang CH, Kebabian JW (1991) Activation of the 5-HT1C receptor expressed in Xenopus oocytes by the benzazepines SCH 23390 and SKF 38393. Br J Pharmacol 104:1038-1044.

Cameron DL, Williams JT (1993) Dopamine D1 receptors facilitate transmitter release. Nature 366:344-347.

Carr DB, Sesack SR (2000) Projections from the rat prefrontal cortex to the ventral tegmental area: target specificity in the synaptic associations with mesoaccumbens and mesocortical neurons. J Neurosci 20:3964-3873.

Chen NH, Reith ME (1994) Autoregulation and monoamine interactions in the ventral tegmental area in the absence and presence of cocaine: a microdialysis study in freely moving rats. J Pharmacol Exp Ther 271:1597-1610.

Christoffersen CL, Meltzer LT (1995) Evidence for $N$-methyl-Daspartate and AMPA subtypes of the glutamate receptor on substantia nigra dopamine neurons: possible preferential role for $N$-methyl-Daspartate receptors. Neuroscience 67:373-381.

Ciccocioppo R, Ge J, Barnes NM, Cooper SJ (1997) Autoradiographic mapping of brain 5-HT2A binding sites in P and in AA alcoholpreferring rats. Brain Res Bull 44:33-37.

de Wit H, Wise RA (1977) Blockade of cocaine reinforcement in rats with the dopamine receptor blocker pimozide, but not with noradrenergic blockers phentolamine and phenoxybenzamine. Can J Psychol 31:195-203

Di Chiara G, Imperato A (1988) Drugs abused by humans preferentially increase synaptic dopamine concentrations in the mesolimbic system of freely moving rats. Proc Natl Acad Sci USA 85:5274-5278.

Eberle-Wang K, Mikeladze Z, Uryu K, Chesselet MF (1997) Pattern of expression of the serotonin $2 \mathrm{C}$ receptor messenger RNA in the basal ganglia of adult rats. J Comp Neurol 384:233-247.

Ettenberg A, Camp CH (1986a) Haloperidol induces a partial reinforcement extinction effect in rats: implications for a dopamine involvement in food reward. Pharmacol Biochem Behav 25:813-821.

Ettenberg A, Camp CH (1986b) A partial reinforcement extinction effect in water-reinforced rats intermittently treated with haloperidol. Pharmacol Biochem Behav 25:1231-1235.

Ettenberg A, Pettit HO, Bloom FE, Koob GF (1982) Heroin and cocaine intravenous self-administration in rats: mediation by separate neural systems. Psychopharmacology 78:204-209.

Fibiger HC (1978) Drugs and reinforcement mechanisms: a critical review of the catecholamine theory. Ann Rev Pharmacol Toxicol 18:37-56.

Fouriezos G, Wise RA (1976) Pimozide-induced extinction of intracranial self-stimulation: response patterns rule out motor or performance deficits. Brain Res 103:377-380.

Franklin K (1978) Catecholamines and self-stimulation: reward and performance effects dissociated. Pharmacol Biochem Behav 9:813-820.

Gerber GJ, Sing J, Wise RA (1981) Pimozide attenuates lever pressing for water reinforcement in rats. Pharmacol Biochem Behav 14:201-205.

Harrison MB, Wiley RG, Wooten GF (1990) Selective localization of striatal D1 receptors to striatonigral neurons. Brain Res 528:317-322.

Herkenham M, Lynn AB, de Costa BR, Richfield EK (1991) Neuronal localization of cannabinoid receptors in the basal ganglia of the rat. Brain Res 547:267-274.

Hicks PE, Schoemaker H, Langer SZ (1984) 5-HT receptor antagonist properties of SCH 23390 in vascular smooth muscle and brain. Eur J Pharmacol 105:339-343.

Hoyer D, Waeber C, Schoeffter P, Palacios JM, Dravid A (1989) 5-HT1C receptor-mediated stimulation of inositol phosphate production in pig choroid plexus. A pharmacological characterization. Naunyn Schmiedebergs Arch Pharmacol 339:252-258.

Hyttel J (1983) SCH 23390: the first selective dopamine D1 antagonist. Eur J Pharmacol 91:153-154.

Iorio LC, Barnett A, Leitz FH, Houser VP, Korduba CA (1983) SCH 23390 , a potential benzazepine antipsychotic with unique interactions on dopaminergic systems. J Pharmacol Exp Ther 226:462-468.

Jackson EA, Kelly PH (1983) Nigral dopaminergic mechanisms in druginduced circling. Brain Res Bull 11:605-611.

Johnson AK, Epstein AN (1975) The cerebral ventricles as the avenue for the dipsogenic action of intracranial angiotensin. Brain Res 86:399-418.

Kalivas PW (1993) Neurotransmitter regulation of dopamine neurons in the ventral tegmental area. Brain Res Rev 18:75-113. 
Kalivas PW, Duffy P (1993) Time course of extracellular dopamine and behavioral sensitization to cocaine. II. Dopamine perikarya. J Neurosci 13:276-284.

Kalivas PW, Duffy P (1995) D1 receptors modulate glutamate transmission in the ventral tegmental area. J Neurosci 15:5379-5388.

Koob GF, Bloom FE (1988) Cellular and molecular mechanisms of drug dependence. Science 242:715-723.

Lacosta S, Roberts DCS (1993) MDL 72222, ketanserin, and methysergide pretreatments fail to alter breaking points on a progressive ratio schedule reinforced by intravenous cocaine. Pharmacol Biochem Behav 44:161-165.

LaHoste GJ, Marshall JF (1990) Nigral D1 and striatal D2 receptors mediate the behavioral effects of dopamine agonists. Behav Brain Res 38:233-242.

Leysen JE, Awouters F, Kennis L, Laduron PM, Vandenberk J, Janssen PA (1981) Receptor binding profile of R 41 468, a novel antagonist at 5-HT2 receptors. Life Sci 28:1015-1022.

Lu X-Y, Churchill L, Kalivas PW (1997) Expression of D1 receptor mRNA in projections from the forebrain to the ventral tegmental area. Synapse 25:205-214.

Ma SY, Ciliax BJ, Stebbins G, Jaffar S, Joyce JN, Cochran EJ, Kardower JH, Mash DC, Levey AI, Mufson EJ (1999) Dopamine transporterimmunoreactive neurons decrease with age in the human substantia nigra. J Comp Neurol 409:25-37.

Maldonado R, Robledo P, Chover AJ, Caine SB, Koob GF (1993) D dopamine receptors in the nucleus accumbens modulate cocaine selfadministration in the rat. Pharmacol Biochem Behav 45:239-242.

McGregor A, Roberts DCS (1993) Dopaminergic antagonism within the nucleus accumbens or the amygdala produces differential effects on intravenous cocaine self-administration under fixed and progressive ratio schedules of reinforcement. Brain Res 624:245-252.

McGregor A, Roberts DCS (1995) Effect of medial prefrontal cortex injections of SCH 23390 on intravenous cocaine self-administration under both a fixed and progressive ratio schedule of reinforcement. Behav Brain Res 67:75-80.

Moghaddam B, Bunney BS (1989) Differential effect of cocaine on extracellular dopamine levels in rat medial prefrontal cortex and nucleus accumbens: comparison to amphetamine. Synapse 4:156-161.

Nakanishi S (1992) Molecular diversity of glutamate receptors and implications for brain function. Science 258:597-603.

Overton P, Clark D (1992) Iontophoretically administered drugs acting at the $N$-methyl-D-aspartate receptor modulate burst firing in A9 dopamine neurons in the rat. Synapse 10:131-140.

Paxinos G, Watson C (1986) The rat brain in stereotaxic coordinates. New York: Academic.

Pfaus JG, Phillips AG (1989) Differential effects of dopamine receptor antagonists on the sexual behavior of male rats. Psychopharmacology 98:363-368.

Porrino LJ, Ritz MC, Goodman NL, Sharpe LG, Kuhar MJ, Goldberg SR (1989) Differential effects of the pharmacological manipulation of serotonin systems on cocaine and amphetamine self-administration in rats. Life Sci 45:1529-1535.

Richardson NR, Roberts DCS (1996) Progressive ratio schedules in drug self-administration studies in rats: a method to evaluate reinforcing efficacy. J Neurosci Methods 66:1-11.

Roberts DCS, Corcoran ME, Fibiger HC (1977) On the role of ascend- ing catecholaminergic systems in intravenous self-administration of cocaine. Pharmacol Biochem Behav 6:615-620.

Schultz W (1997) A neural substrate of prediction and reward. Science 275:1593-1599.

Sesack SR, Pickel VM (1992) Prefrontal cortical efferents in the rat synapse on unlableled neuronal targets of catecholamine terminals in the nucleus accumbens septi and on dopamine neurons in the ventral tegmental area. J Comp Neurol 320:145-160.

Smith Y, Charara A, Parent A (1996) Synaptic innervation of midbrain dopaminergic neurons by glutamate-enriched terminals in the squirrel monkey. J Comp Neurol 364:231-253.

Starr M (1987) Opposing roles of dopamine $\mathrm{D}_{1}$ and $\mathrm{D}_{2}$ receptors in nigral $\left[{ }^{3} \mathrm{H}\right]$ aminobutyric acid release? J Neurochem 49:1042-1049.

Steffensen SC, Svingos AL, Pickel VM, Henriksen SJ (1998) Electrophysiological characterization of GABAergic neurons in the ventral tegmental area. J Neurosci 18:8003-8015.

Stewart J, Vezina P (1989) Microinjections of Sch-23390 into the ventral tegmental area and substantia nigra pars reticulata attenuate the development of sensitization to the locomotor activating effects of systemic amphetamine. Brain Res 495:401-406.

Tepper JM, Martin LP, Anderson DR (1995) GABA A receptormediated inhibition of rat substantia nigra dopaminergic neurons by pars reticulata projection neurons. J Neurosci 15:3092-3103.

Wise RA (1978) Catecholamine theories of reward: a critical review. Brain Res 152:215-247.

Wise RA (1996) Neurobiology of addiction. Curr Opin Neurobiol $6: 243-251$.

Wise RA, Hoffman DC (1992) Localization of drug reward mechanisms by intracranial injections. Synapse 10:247-263.

Wise RA, Rompré P-P (1989) Brain dopamine and reward. Annu Rev Psychol 40:191-225.

Wise RA, Spindler J, deWit H, Gerber GJ (1978) Neuroleptic-induced "anhedonia" in rats: pimozide blocks reward quality of food. Science 201:262-264.

Woodward RM, Panicker MM, Miledi R (1992) Actions of dopamine and dopaminergic drugs on cloned serotonin receptors expressed in Xenopus oocytes. Proc Natl Acad Sci USA 89:4708-4712.

Yokel RA, Wise RA (1975) Increased lever pressing for amphetamine after pimozide in rats: implications for a dopamine theory of reward. Science 187:547-549.

Yokel RA, Wise RA (1976) Attenuation of intravenous amphetamine reinforcement by central dopamine blockade in rats. Psychopharmacology 48:311-318.

Yung KK, Bolam JP, Smith AD, Hersch SM, Ciliax BJ, Levey AI (1995) Immunocy tochemical localization of D1 and D2 dopamine receptors in the basal ganglia of the rat: light and electron microscopy. Neuroscience 65:709-730.

Zetterström T, Sharp T, Marsden CA, Ungerstedt U (1983) In vivo measurement of dopamine and its metabolites by intracerebral dialysis: changes after D-amphetamine. J Neurochem 41:1769-1773.

Zhang J, Chiodo LA, Freeman AS (1994) Influence of excitatory amino acid receptor subtypes on the electrophysiological activity of dopaminergic and nondopaminergic neurons in rat substantia nigra. J Pharmacol Exp Ther 269:313-321.

Zito KA, Vickers GJ, Roberts DCS (1985) Disruption of cocaine and heroin self-administration following kainic acid lesions of the nucleus accumbens. Pharmacol Biochem Behav 23:1029-1036. 